\title{
The use of induced sputum in clinical trials
}

\author{
Leader of the Working Group: J.C. Kips* \\ Members of the Working Group: M.D. Inman\#, L. Jayaram", E.H. Bel ${ }^{+}$, K. Parameswaran ${ }^{\S}$, \\ M.M.M. Pizzichinif ${ }^{\prime}$, I.D. Pavord**, R. Djukanović\#\#, F.E. Hargreave ${ }^{\#}$, P.J. Sterk ${ }^{+}$
}

As asthma is considered to be an inflammatory disorder of the airways, it seems logical to include an assessment of this inflammatory process as an outcome measure in clinical trials. Biopsy studies illustrate that clinical or lung function characteristics such as symptoms, peak flow variability or degree of airway responsiveness do not consistently correlate with histological alterations. Therefore, these clinical indices cannot be seen as accurate markers of airway inflammation [1-3]. Conversely, repeated bronchoscopic sampling is not feasible in large-scale clinical studies. Hence there is interest in a relatively noninvasive but direct marker of airway inflammation.

Analysis of induced sputum seems to meet these criteria. Provided proper precautions are taken, induction of sputum is safe, even in patients with more severe asthma $[4,5]$. In addition, sputum cell counts, particularly eosinophil counts, have been well validated in terms of responsiveness to intervention. It has been argued that, in comparison with other noninvasive markers of inflammation, induced sputum offers the most balanced assessment of the degree of inflammation, being more responsive to intervention than serum eosinophil cationic protein, yet not as oversensitive as exhaled nitric oxide [6-8].

As for any outcome measure, when including induced sputum in a clinical trial, specific features of sputum analysis need to be taken into account when designing the study: 1) origin of sputum; 2) methodological aspects; 3) selection of subjects; and 4) power calculations.

\section{Origin of sputum}

The induced sputum technique samples the inflammatory cells and soluble markers present in the airway lumen of the bronchial tree, which, although reflective of, does not represent an identical situation to the local inflammatory process in the mucosa. This probably explains the poor correlation between the cellular composition of biopsy samples and sputum, bronchial wash or bronchoalveolar lavage [9-11]. Therefore, although induced sputum can provide information regarding the ongoing overall inflammation in asthma, it might not be the ideal substrate for studying the exact pathophysiological events that occur within the airway wall.

\section{Methodological aspects}

Regarding the use of induced sputum in clinical trials, a few methodological issues should be re-emphasised. Consecutive inductions within a short time interval can cause an increase in the percentage of neutrophils in sputum $[12,13]$. It has also been reported that the composition of sputum can change somewhat throughout the duration of the induction procedure and that standardising this variable would seem advisable [14]. Current recommendations are to process sputum samples within $2 \mathrm{~h}$ after induction, although a recent study has shown that this can be prolonged to 9 h (A. Efthimiadis, Firestone Institute for Respiratory Health, Hamilton, Ontario, Canada, personal communication). This can be important when deciding on the number and timing of inductions to be performed.

\section{Selection of subjects}

It should be remembered that, to date, analysis of induced sputum has mainly been validated with regard to the percentage of eosinophils in the cell pellet. The responsiveness to intervention of other possible outcome measures, be they cells or soluble mediators, has been far less thoroughly established.

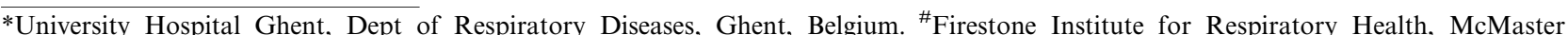
University, Hamilton, Ontario, Canada. 'Respiratory and Sleep Disorders Unit, Repatriation General Hospital, Daw Park, South Australia, Australia. ${ }^{+}$Dept of Pulmonology, Leiden University Medical Centre, Leiden, the Netherlands. ${ }^{\S}$ FRCAU, St. Joseph's Hospital, Hamilton, Ontario, Canada. ${ }^{f}$ Asthma Research Centre, University Hospital, Federal University of Santa Catarina, Florianópolis, Santa Catarina, Brazil. **Institute for Lung Health, Dept of Respiratory Medicine and Thoracic Surgery, Glenfield Hospital, Leicester, UK. \#\# Southampton University General Hospital, Southampton, UK.

Correspondence: J.C. Kips, University Hospital Ghent, Dept of Respiratory Diseases, De Pintelaan 185, 9000 Ghent, Belgium. Fax: 32 9 2402341. E-mail: johan.kips@rug.ac.be
}

Received: April 4 2002; Accepted: April 162002 
The use of eosinophil counts as the main outcome measure of the induced sputum technique requires specific consideration, in part related to the overall aim of the study planned, to be given to the screening of patients for study inclusion. If the aim of the study is to evaluate the biological activity of a given compound on eosinophils, it is acceptable to select subjects based on the number of eosinophils in their sputum samples. However, this does not apply if the aim of the study is to conduct a clinical trial in asthma as a disease entity. Although sputum eosinophil counts in samples obtained from the same patient on different occasions are repeatable, the interindividual variability is large, even in samples obtained from patients with very similar clinical characteristics $[15,16]$.

Therefore, including only those patients with a specific degree of sputum eosinophilia leads to a selection bias that hampers a proper interpretation and generalisation of the results.

Another point that must be considered is that, when subjects are randomised based on lung function or clinical criteria, the wide variability in sputum eosinophilia can cause unexpected differences between the groups, at baseline. An approach to preventing this is to stratify patients at randomisation to ensure that the full range of baseline eosinophilia is equally represented in each study group [17]. It can only be used in proof of concept studies aimed at reducing numbers of sputum eosinophils.

\section{Power calculations}

An important consideration in the design of most clinical trials is estimation of the appropriate sample size required to draw adequate conclusions from the study. This depends on the set probability of making a type I ( $\alpha$ level) or type II ( $\beta$ level) error, the design of the study, the reliability of the outcome measurement and the desired effect size. The $\alpha$ level or probability of falsely rejecting the null hypothesis is usually set at $5 \%$. The $\beta$ level represents the probability of falsely accepting the null hypothesis, usually set at $10-20 \%$. Hence, 1- $\beta$, the power of the study, expresses the probability of avoiding a type II error. The power of the study relates intimately to the variability in the outcome measurement (either inter- or intrasubject, depending on study design) and the desired effect size. The present authors strongly recommend that researchers determine sample size requirements based on the variability and reproducibility of sputum eosinophil counts in their own population. A less favoured option is to rely on data from the literature, taking into account the induction and processing techniques used. As an example, duplicate measurements were examined from 84 volunteer subjects from multiple centres (table 1). All of these subjects had been diagnosed with asthma and were not currently receiving anti-inflammatory treatment. No intervention took place between the two sputum measurements, which were separated by $\sim 1$ week. The formula used to determine sample size requirement is $\left(\mathrm{T}_{1-\alpha / 2}+\mathrm{T}_{1-\beta}\right) \phi / \mathrm{LCID}$,
Table 1.-Eosinophil counts in duplicate sputum samples obtained from asthmatic subjects currently not on maintenance treatment

\begin{tabular}{lccc}
\hline & Sample & Sample & Difference \\
& 1 & 2 & \\
\hline $\begin{array}{c}\text { Mean } \log _{10} \text {-transformed } \\
\text { data }\end{array}$ & 0.674 & 0.672 & 0.002 \\
$\begin{array}{c}\text { SD } \log _{10} \text {-transformed } \\
\text { data }\end{array}$ & 0.729 & 0.743 & 0.333 \\
Geometric mean & 4.722 & 4.698 & \\
\hline
\end{tabular}

where $\mathrm{T}$ is score of the paired t-test corresponding to the desired $\alpha$ and power $(1-\beta), \phi$ is the standard deviation of the outcome of interest and LCID is the least clinically important difference. When designing a parallel study, $\phi$ relates to the interindividual variability in eosinophil count, whereas, in a crossover study, the variable of interest is the intrasubject reproducibility. An alternative consists of feeding these data into power tables. This allows the determination of the sample size required to draw conclusions with various levels of confidence regarding the significance of a predefined difference in eosinophil count over the study period within or between groups. An example is given in figure 1. These data are based on the reproducibility of changes in sputum eosinophil count following allergen challenge. From these data, it would appear that, when performing repeated measures analysis of variance on sputum samples obtained at 7 and $24 \mathrm{~h}$ after allergen challenge, the estimated sample size required to observe a $50 \%$ attenuation of allergen-induced increase in the percentage of eosinophils in a crossover study design is only five subjects. As total cell counts in sputum show poorer reproducibility, using total counts instead of percentage of eosinophils increases the estimated sample size

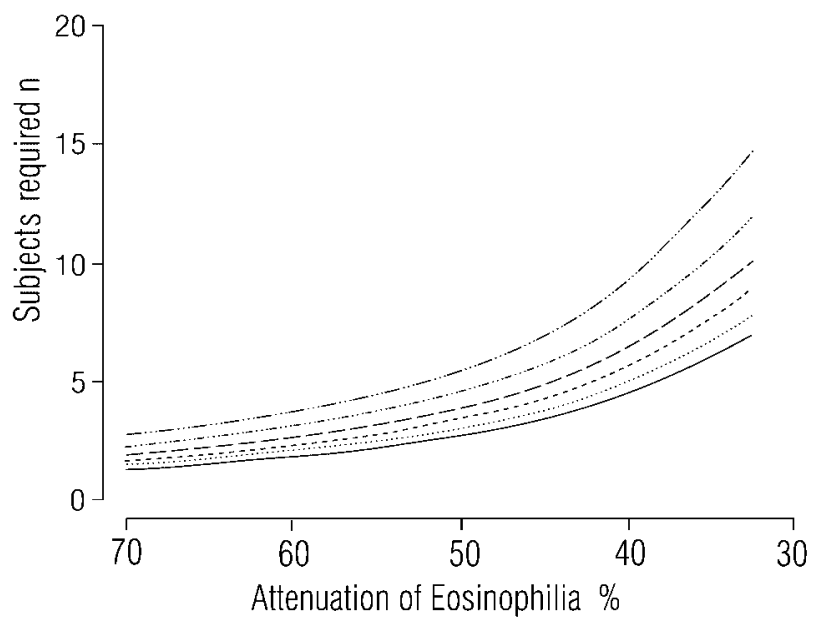

Fig. 1.-Sample size requirements for demonstrating statistically significant attenuation of allergen-induced increases in percentage of sputum eosinophils (power: - $: 0.70 ; \cdots \cdots \cdots . .6$ : 0.75 ; ----: 0.80 ; - - - -: 0.85; --..--..--: $0.90 ;-\ldots-\ldots-$ : 0.95$)$. For example, a drug that blocks $50 \%$ of the allergen-induced increase in eosinophil number can be demonstrated to be significant using only four subjects $(90 \%$ power $)$. 
Table 2. - The attenuating effect of various steroid formulations, doses and treatment durations on sputum eosinophils. Improvements are expressed as percentage improvement from a pre-treatment baseline

\begin{tabular}{|c|c|c|c|c|}
\hline First author [Ref.] & Steroid & Dose $\mu \mathrm{g}$ & $\begin{array}{c}\text { Duration } \\
\text { weeks }\end{array}$ & $\begin{array}{c}\text { Improvement } \\
\%\end{array}$ \\
\hline \multirow[t]{2}{*}{ JATAKANON [8] } & Bud & 100 & 4 & 69 \\
\hline & Bud & 400 & 4 & 71 \\
\hline ALDRIDGE [22] & Bud & 800 & 6 & 61 \\
\hline \multirow[t]{3}{*}{ TAYLOR [23] } & Cicl & 100 & 2 & 36 \\
\hline & Cicl & 400 & 2 & 65 \\
\hline & $\mathrm{Cicl}$ & 1600 & 2 & 63 \\
\hline LIM [24] & Bud & 1600 & 4 & 71 \\
\hline FAHY [25] & $\mathrm{BDP}$ & 336 & 4 & 6 \\
\hline TURNER [26] & BDP & 336 & 4 & 75 \\
\hline BACCI $[27]$ & Bud & 400 & 3 months & 91 \\
\hline VAN RENSEN [28] & FP & 1000 & 4 & 85 \\
\hline KEATINGS [29] & PRED & $30 \mathrm{mg}$ & 2 & 86 \\
\hline Claman [30] & PRED & $0.5 \mathrm{mg} \cdot \mathrm{kg}^{-1}$ & 6 days & 87 \\
\hline
\end{tabular}

Bud: budesonide; Cicl: ciclosporin; BDP: beclomethasone dipropionate; FP: fluticasone propionate; PRED: prednisone.

required from five to 21 , for the same level of power, desired effect size and study design [18].

A more difficult element is how to determine the desired effect size. A first possibility is to aim at normalisation of sputum eosinophil counts. Increasing evidence based on studies in healthy volunteers indicates that a normal range of sputum eosinophils in adults and children is $<2.5 \%$ [19-21]. However, any form of treatment rarely achieves full normalisation of all outcome measures in asthma. To date, it is uncertain whether reducing eosinophil counts, in addition to treating symptoms or lung function characteristics, improves the long-term clinical outcome of the disease. As a consequence, it is equally unclear what constitutes a "least clinically important difference" (LCID) as opposed to a statistically significant change in sputum eosinophil count. What has been shown is that an allergen inhalation challenge that causes a late asthmatic response is associated with an approximately five-fold increase in sputum eosinophil numbers [18]. Conversely, treatment with steroids reduces sputum eosinophil counts. In the various studies reported to date, oral or inhaled steroids were given at different doses for varying time periods. It is therefore difficult to compare these various studies, but, overall, it would seem that inhaled steroids from low doses onwards, offer a $\geqslant 60 \%$ reduction in median sputum eosinophil percentage (table 2). These data indicate that sputum eosinophilia changes substantially in response to intervention. It could therefore be proposed that the LCID should be a $\geqslant 50 \%$ change in sputum eosinophil count.

Of interest is that, from the limited amount of data available, it would seem that, as for clinical outcome measures such as symptom score or peak flow, the dose/response curve for the effect of inhaled steroids on sputum eosinophil counts is rather flat [8]. Importantly, however, the change in eosinophil count does not always correlate with the degree of clinical improvement $[24,25,28,31]$, thus further suggesting that measurement of sputum eosinophil number could offer complementary information to mere clinical follow-up.

\section{Key points}

1) Analysis of induced sputum has only been validated for the percentage of eosinophils in the cell pellet; 2) the interindividual variability in sputum eosinophilia is large even in subjects with similar clinical characteristics; and 3) the least clinically important difference in sputum eosinophil counts remains to be established.

\section{Outstanding questions}

1) The least clinically important difference in sputum eosinophil counts remains to be established; and 2) the prognostic significance of reductions in sputum eosinophil count on the long-term clinical outcome in asthma needs to be investigated.

\section{References}

1. Crimi E, Spanevello A, Neri M, Ind PW, Rossi GA, Brusasco V. Dissociation between airway inflammation and airway hyperresponsiveness in allergic asthma. Am J Respir Crit Care Med 1998; 157: 4-9.

2. Djukanovic R, Wilson JW, Britten KM, et al. Quantitation of mast cells and eosinophils in the bronchial mucosa of symptomatic atopic asthmatics and healthy control subjects using immunohistochemistry. Am Rev Respir Dis 1990; 142: 863-871.

3. Roisman GL, Lacronique JG, Desmazes-Dufeu N, Carre C, Le Cae A, Dusser DJ. Airway responsiveness to bradykinin is related to eosinophilic inflammation in asthma. Am J Respir Crit Care Med 1996; 153: 381390.

4. de la Fuente PT, Romagnoli M, Godard P, Bousquet J, Chanez P. Safety of inducing sputum in patients with asthma of varying severity. Am J Respir Crit Care Med 1998; 157: 1127-1130.

5. Pizzichini MM, Pizzichini E, Clelland L, et al. Sputum in severe exacerbations of asthma: kinetics of inflammatory indices after prednisone treatment. $A m J$ Respir Crit Care Med 1997; 155: 1501-1508. 
6. McIvor RA, Pizzichini E, Turner MO, Hussack P, Hargreave FE, Sears MR. Potential masking effects of salmeterol on airway inflammation in asthma. Am J Respir Crit Care Med 1998; 158: 924-930.

7. Berlyne GS, Parameswaran K, Kamada D, Efthimiadis A, Hargreave FE. A comparison of exhaled nitric oxide and induced sputum as markers of airway inflammation. J Allergy Clin Immunol 2000; 106: 638644.

8. Jatakanon A, Kharitonov S, Lim S, Barnes PJ. Effect of differing doses of inhaled budesonide on markers of airway inflammation in patients with mild asthma. Thorax 1999; 54: 108-114.

9. Fahy JV, Wong H, Liu J, Boushey HA. Comparison of samples collected by sputum induction and bronchoscopy from asthmatic and healthy subjects. Am J Respir Crit Care Med 1995; 152: 53-58.

10. Maestrelli P, Saetta M, Di Stefano A, et al. Comparison of leukocyte counts in sputum, bronchial biopsies, and bronchoalveolar lavage. Am J Respir Crit Care Med 1995; 152: 1926-1931.

11. Keatings VM, Evans DJ, O'Connor BJ, Barnes PJ. Cellular profiles in asthmatic airways: a comparison of induced sputum, bronchial washings, and bronchoalveolar lavage fluid. Thorax 1997; 52: 372-374.

12. Nightingale JA, Rogers DF, Barnes PJ. Effect of repeated sputum induction on cell counts in normal volunteers. Thorax 1998; 53: 87-90.

13. Holz O, Richter K, Jorres RA, Speckin P, Mucke M, Magnussen H. Changes in sputum composition between two inductions performed on consecutive days. Thorax 1998; 53: 83-86.

14. Gershman NH, Liu H, Wong HH, Liu JT, Fahy JV. Fractional analysis of sequential induced sputum samples during sputum induction: evidence that different lung compartments are sampled at different time points. J Allergy Clin Immunol 1999; 104: 322328.

15. Pizzichini E, Pizzichini MM, Efthimiadis A, et al. Indices of airway inflammation in induced sputum: reproducibility and validity of cell and fluid-phase measurements. Am J Respir Crit Care Med 1996; 154: 308-317.

16. in't Veen JC, de Gouw HW, Smits HH, et al. Repeatability of cellular and soluble markers of inflammation in induced sputum from patients with asthma. Eur Respir J 1996; 9: 2441-2447.

17. Lavori PH, Louis TA, Bailar IJC, Polansky M. Parallel comparisons of treatment. In: Bailar JC III, Mosteller F, eds. Medical Uses of Statistics. Waltham, MA, NEJM Books, 1996; pp. 41-66.

18. Gauvreau GM, Watson RM, Rerecich TJ, Baswick E, Inman MD, O'Byrne PM. Repeatability of allergeninduced airway inflammation. J Allergy Clin Immunol 1999; 104: 66-71.

19. Belda J, Leigh R, Parameswaran K, O'Byrne PM,
Sears MR, Hargreave FE. Induced sputum cell counts in healthy adults. Am J Respir Crit Care Med 2000; 161: 475-478.

20. Spanevello A, Confalonieri M, Sulotto F, et al. Induced sputum cellularity: reference values and distribution in normal volunteers. Am J Respir Crit Care Med 2000; 162: 1172-1174.

21. Gibson PG, Henry RL, Thomas P. Noninvasive assessment of airway inflammation in children: induced sputum, exhaled nitric oxide, and breath condensate. Eur Respir $J$ 2000; 16: 1008-1015.

22. Aldridge RE, Hancox RJ, Taylor DR, et al. Effects of terbutaline and budesonide on sputum cells and bronchial hyperresponsiveness in asthma. Am J Respir Crit Care Med 2000; 161: 1459-1464.

23. Taylor DA, Jensen MW, Kanabar V, et al. A dosedependent effect of the novel inhaled corticosteroid ciclesonide on airway responsiveness to adenosine-5'monophosphate in asthmatic patients. Am J Respir Crit Care Med 1999; 160: 237-243.

24. Lim S, Jatakanon A, John M, et al. Effect of inhaled budesonide on lung function and airway inflammation: assessment by various inflammatory markers in mild asthma. Am J Respir Crit Care Med 1999; 159: 22-30.

25. Fahy JV, Boushey HA. Effect of low-dose beclomethasone dipropionate on asthma control and airway inflammation. Eur Respir J 1998; 11: 12401247.

26. Turner MO, Johnston PR, Pizzichini E, Pizzichini MM, Hussack PA, Hargreave FE. Anti-inflammatory effects of salmeterol compared with beclomethasone in eosinophilic mild exacerbations of asthma: a randomized, placebo controlled trial. Can Respir J 1998; 5: 261-268.

27. Bacci E, Cianchetti S, Ruocco L, et al. Comparison between eosinophilic markers in induced sputum and blood in asthmatic patients. Clin Exp Allergy 1998; 28: 1237-1243.

28. van Rensen EL, Straathof KC, Veselic-Charvat MA, Zwinderman AH, Bel EH, Sterk PJ. Effect of inhaled steroids on airway hyperresponsiveness, sputum eosinophils, and exhaled nitric oxide levels in patients with asthma. Thorax 1999; 54: 403-408.

29. Keatings VM, Jatakanon A, Worsdell YM, Barnes PJ. Effects of inhaled and oral glucocorticoids on inflammatory indices in asthma and COPD. $\mathrm{Am}$ J Respir Crit Care Med 1997; 155: 542-548.

30. Claman DM, Boushey HA, Liu J, Wong H, Fahy JV. Analysis of induced sputum to examine the effects of prednisone on airway inflammation in asthmatic subjects. J Allergy Clin Immunol 1994; 94: 861-869.

31. Gershman NH, Wong HH, Liu JT, Fahy JV. Lowand high-dose fluticasone propionate in asthma; effects during and after treatment. Eur Respir $J$ 2000; 15: 11-18. 